\title{
ATIVIDADES DE NITROGENASE E REDUTASE DE NITRATO E PRODUTIVIDADE DO FEIJ OEIRO “OURO NEGRO” EM RESPOSTA À ADUBAÇÃO FOLIAR COM MOLIBDÊNIO(1)
}

\author{
A. C.S. PESSOA ${ }^{(2)+}$, A. C. RIBEIRO(3), \\ J. M. CHAGAS ${ }^{(4)} \&$ S.T. A. CASSINI ${ }^{(5)}$
}

\begin{abstract}
RESUMO
A efetividade do suprimento de nitrogênio ao feijoeiro, por meio de fertilizante e, ou, de fixação biológica, e a dependência desses processos à disponibilidade de molibdênio constituem, ainda, um problema mal resolvido. Objetivando avaliar os efeitos da aplicação foliar de Mo na atividade das enzimas nitrogenase e redutase do nitrato e na produtividade do feijoeiro, realizou-se um experimento, em condições de campo, em um Podzólico Vermelho-Amarelo do município de Coimbra (MG). Os tratamentos constituíram-se de doses crescentes de Mo (0, 40, 80 e $\left.120 \mathrm{~g} \mathrm{ha}^{-1} \mathrm{de} \mathrm{Mo}\right)$, aplicadas em adubação foliar aos 25 dias da emergência. $\mathrm{Na}$ adubação de base, usaram-se $20 \mathrm{~kg} \mathrm{ha}^{-1} \mathrm{de} \mathrm{N} \mathrm{e} 60 \mathrm{~kg} \mathrm{ha}^{-1}$ de $\mathrm{K}_{2} \mathrm{O}$. Não foi aplicado nitrogênio em cobertura. A aplicação foliar de Mo aumentou as atividades da nitrogenase e da redutase do nitrato, mantendo-as em patamares mais altos durante o ciclo da cultura, proporcionando maiores teores de $\mathbf{N}$ nas folhas e maior produtividade. A eficiência máxima foi alcançada com $80 \mathrm{~g} \mathrm{ha}^{-1}$ de Mo, com produtividade de $1.893 \mathrm{~kg} \mathrm{ha}^{-1}$ de grãos, 3,23 vezes maior que a da testemunha (sem Mo). A aplicação foliar de Mo aumentou, também, em 1,54 vez o número de vagens por planta, em 0,23 o número de grãos por vagem e em 0,15 o peso de 100 grãos, em comparação ao tratamento que não recebeu Mo.
\end{abstract}

Termos de indexação: enzi mas, micronutriente, Phaseol us vulgaris, nitrogênio.

\footnotetext{
(1) Parte da Tese de Doutorado do primeiro autor. Trabalho financiado pela FAPEMIG e apresentado na XXIII Reunião Bras. Fertilidade do Solo e Nutrição de Plantas (FertBio-98), Caxambu, 11 a 16 de outubro de 1998. Recebido para publicação em março de 1999 e aprovado em outubro de 2000.

(2)† Professor Adjunto do Departamento de Agronomia da Universidade Estadual do Oeste do Paraná (U NIOESTE). CEP 85960-000 Mal. Cândido Rondon (PR).

(3) Professor Titular aposentado do Departamento de Solos da U niversidade Federal de Viçosa (UFV). CEP 36571-000 Viçosa (MG), pesquisador visitante EPAMIG. Bolsista da FAPEMIG.

(4) Pesquisador da EPAMIG, Coordenador do projeto de pesquisa, Viçosa (MG).

(5) Professor Titular do Departamento de Microbiologia, UFV.
} 


\title{
SUMMARY: NIROGENASE AND NITRATE REDUCTASE ACTIVITIES AND PRODUCTIVITY OF COMMON BEANS IN RESPONSE TO FOLIAR APPLICATION OF MOLIBDENUM
}

\begin{abstract}
Theeffectiveness of thenitrogen supplying to bean plants as fertilizer and, or, as bi ological nitrogen fixation, and the dependence of these processes on moli ibdenum availability is still a not well solved problem. The objective of this study was to evaluate the effect of foliar application of Mo on nitrogenase and nitrate reductase activities and on productivity of beans cultivated on a Red Yellow Podzolic, in Coi mbra, MG (Brazil). Thetreatments consisted of increasing rates of foliar application of $\mathrm{Mo}\left(0,40,80\right.$ and $\left.120 \mathrm{~g} \mathrm{ha}^{-1}\right) 25$ days after emergence. Fertilization was $20 \mathrm{~kg} \mathrm{ha}^{-1}$ of $\mathrm{N}$ and $60 \mathrm{~kg} \mathrm{ha}^{-1}$ of $\mathrm{K}_{2} \mathrm{O}$ applied during seeding. NoN was applied afterwards. F oliar application of Mo increased and maintained nitrogenase and nitrate reductase activities during the whole plant growth cycle. Consequently, better crop productivities wereobtained compared to theplants from thecontrol. Maximum technical efficiency was obtained with $80 \mathrm{~g} \mathrm{ha}^{-1}$ of Mo with productivity of $1,893 \mathrm{~kg} \mathrm{ha}^{-1}$ of beans wich was 3.23 higher than that of the plants without M o fertilization. Fol iar application of Mo increased the number of pods per plant in 1.54 fold, the number of grains per pod in 0.23 , and the weight of 100 grains in 0.15 compared to the control.
\end{abstract}

Index terms: enzymes, micronutrient, Phaseolus vul garis, nitrogen.

\section{INTRODUÇÃO}

A produtividade do feijoeiro está diretamente relacionada com sua nutrição nitrogenada (Vieira et al., 1992; Vieira et al., 1998). O metabolismo do nitrogênio pode ser seriamente prejudicado em plantas submetidas à deficiência de molibdênio, pelo seu envolvimento nas enzimas redutase do nitrato e nitrogenase.

O feijoeiro, quando em simbiose com bactérias do gênero Rhizobium, é capaz de aproveitar o nitrogênio atmosférico, contribuindo para sua nutrição nitrogenada. Todavia, a efetividade da inoculação dessa cultura ainda é bastantelimitada, não tendo sido obtidas respostas positivas, principalmente em decorrência da baixa eficiência de inoculantes usados e, ou, do manejo inadequado de adubações. Assim, a adubação nitrogenada é freqüentemente utilizada na obtenção de altas produtividades (Araújo et al., 1987). O al to custo dos fertilizantes nitrogenados e as perdas por lixiviação e gasosas, contribuindo com a poluição ambiental, despertam o interesse para o desenvol vimento de técnicas de manejo que possam maximizar o uso eficiente desse nutriente pel o feijoeiro.

Para a efetiva simbiose com o Rhizobium, o feijoei ro tem de estar em sol o com condições ótimas de fertilidade. A esse respeito, é marcante a influência doMo, não só para ocrescimento da planta e da bactéria, como também para a eficiência da simbiose, pelo estímulo à síntese e à atividade da nitrogenase (Marschner, 1995). Assim, a carência desse nutriente poderia ser uma das causas da baixa produtividade da cultura.
Na maioria dos ensaios de adubação com Mo, na Zona da Mata de Minas Gerais, tem-se verificado aumento da produtividade do feijoeiro em resposta à adição desse micronutriente ( $\mathrm{J}$ unqueira Netto et al., 1977; Amane, 1994 e 1997; Coelho, 1997). Conforme Vieira et al. (1992), a aplicação foliar de Mo pode substituir a adubação nitrogenada em cobertura.

A partir dessas considerações, aventou-se a hipótese de diminuir ou até de substituir a adubação nitrogenada de cobertura no feijoeiro pela fixação biológica do $\mathrm{N}_{2}$ pelo Rhizobium, com basena possível influência do Mo. Assim, este trabalho teve como objetivos: verificar os efeitos do M o na atividade das enzimas nitrogenase e redutase do nitrato no feijoeiro em condições de campo, avaliar o efeito da adubação molíbdica sobre a nodulação do feijoei ro e verificar a influência da aplicação de doses crescentes de Mo sobre alguns componentes da produtividade dessa cultura.

\section{MATERIAL E MÉTODOS}

O trabal ho constituiu-se de um cultivo defeijoeiro no outono-inverno de 1996, usando o cv. Ouro Negro, em condições de campo, em Coimbra (MG), em um Podzólico Vermel ho-Amarel o Câmbico fase terraço (Quadro 1).

Usou-se o delineamento experimental de blocos ao acaso, com quatro repetições. Os tratamentos constituíram-se de doses crescentes de Mo (zero, 40, 80 e120 $\left.\mathrm{g} \mathrm{ha}^{-1}\right)$. O experimento recebeu uma adubação 


\section{Quadro 1. Análises químicas e físicas de uma amostra do solo utilizado}

\begin{tabular}{lc}
\hline \multicolumn{1}{c}{ Caracterítica } & Valor \\
\hline $\mathrm{pH}$ em água $(1: 2,5)$ & 5,9 \\
$\mathrm{Mo}\left(\mathrm{mg} \mathrm{dm}^{-3}\right)^{(1,5)}$ & 0,153 \\
$\mathrm{P}\left(\mathrm{mg} \mathrm{dm}^{-3}\right)^{(1)}$ & 6,2 \\
$\mathrm{~K}\left(\mathrm{mg} \mathrm{dm}^{-3}\right)^{(1)}$ & 96 \\
$\mathrm{Al}^{3+}\left(\mathrm{cmol}_{\mathrm{c}} \mathrm{dm}^{-3}\right)^{(2)}$ & 0,0 \\
$\mathrm{Ca}^{2+}\left(\mathrm{cmol}_{\mathrm{c}} \mathrm{dm}^{-3}\right)^{(2)}$ & 4,2 \\
$\mathrm{Mg}^{2+}\left(\mathrm{cmol}_{\mathrm{c}} \mathrm{dm}^{-3}\right)^{(2)}$ & 1,4 \\
$\mathrm{H}+\mathrm{Al}\left(\mathrm{cmol}_{\mathrm{c}} \mathrm{dm}^{-3}\right)^{(3)}$ & 1,2 \\
$\mathrm{SB}\left(\mathrm{cmol}_{\mathrm{c}} \mathrm{dm}^{-3}\right)$ & 5,77 \\
$\mathrm{~V}(\%)$ & 82,8 \\
$\mathrm{~m}(\%)$ & 0,0 \\
$\mathrm{CTC}$ efetiva $\left(\mathrm{cmol}_{\mathrm{c}} \mathrm{dm}^{-3}\right)$ & 5,77 \\
$\mathrm{CTC}$ total $\left(\mathrm{cmol}_{\mathrm{c}} \mathrm{dm}^{-3}\right)$ & 6,97 \\
Areia grossa $(\%)^{(4)}$ & 3 \\
Areia fina $(\%)^{(4)}$ & 2 \\
Silte $(\%)^{(4)}$ & 15 \\
Argila $(\%)^{(4)}$ & 80 \\
Argila dispersa em água (\%)(4) & 39 \\
Classificação textural & Muito argiloso
\end{tabular}

${ }^{(1)}$ Extrator Mehlich-1 (Vettori, 1969). ${ }^{(2)}$ Extrator $\mathrm{KCl} 1 \mathrm{~mol} \mathrm{~L}{ }^{-1}$ (Vettori, 1969). ${ }^{(3)}$ Extrator $\mathrm{Ca}(\mathrm{Oac})_{2} 0,5 \mathrm{~mol} \mathrm{~L}^{-1}$ (Vettori, 1969).

(4) Método da pipeta (EMBRAPA, 1979). ${ }^{(5)}$ Dosagem pel o método do iodeto de potássio (Dallpai, 1996).

básica de potássio na forma de $\mathrm{KCl}$ e de nitrogênio na forma de uréia, no sulco de plantio, nas doses de $60 \mathrm{~kg} \mathrm{ha}^{-1}$ de $_{2} \mathrm{O}$ e $20 \mathrm{~kg} \mathrm{ha}^{-1}$ de N. Não foi aplicado nitrogênio em cobertura, por prejudicar a fixação biológica de nitrogênio.

A aplicação de Mo foi realizada com solução de mol ibdato de amônio aos 25 dias da emergência, com o uso de pulverizador costal, no período entre 7 e 8 horas da manhã.

Cada parcela experimental foi constituída de quatrolinhas desemeadura de 6,0 m decomprimento, espaçadas de $0,5 \mathrm{~m}$. F oram consideradas as duas linhas centrais como parcela útil, eliminando-se 1,0 m de cada extremidade, resultando na área útil de 4,0 $\mathrm{m}^{2}$. Foram utilizadas 17 sementes por metro linear de feijão cv. Ouro Negro, previamente inoculadas com inóculo misto, constituído de Rhizobium tropici (estirpes CIAT 899, SEMIA 487 e BR 281), Rhizobium etli (estirpe CIAT 632) e Rhizobium leguminosarum (estirpes BR 322 e KIM 5), cedidos pelo Laboratório de Microbiologia do Solo da Universidade Federal de Viçosa.

Os demais tratos culturais foram realizados conforme Vieira (1978), evitando-se o uso de inseticidas eherbicidas, principalmente aqueles com princípios tóxicos para o rizóbio. Como no período outono - inverno é comum a deficiência hídrica, realizaram-se irrigações por aspersão quando necessárias.
Para aval iar as atividades da redutase do nitratro (ARN), da nitrogenase e da nodulação, foram realizadas quatro amostragens, aos 20, 40, 55 e 70 dias após a emergência (DAE). U sou-seo método de Hageman \& Reed (1980), com modificações (Coelho, 1997), descritas a seguir.

Inicialmente, foram coletadas, entre as 13:00 e 14:00 h, quatro fol has trifolioladas mais jovens totalmente expandidas. As fol has foram acondicionadas em sacos plásticos, colocadas em caixas de isopor com gel o e levadas rapidamente ao laboratório para a determinação da atividade enzimática in vivo. No laboratório, as folhas foram perfuradas, obtendo-se 50 discos foliares de $0,5 \mathrm{~cm}$ de diâmetro, que foram pesados e, a seguir, colocados em erlenmeyer de $25 \mathrm{~mL}$ que continha $10 \mathrm{~mL}$ do meio de incubação. O mei o de incubação foi composto por $5 \mathrm{~mL}$ de tampão fosfato $0,1 \mathrm{~mol} \mathrm{~L}^{-1}$ a $\mathrm{pH} 7,5$, 2,5 mL de propanol a $8 \%, 1 \mathrm{~mL}$ de água destilada, $1,5 \mathrm{~mL}$ de $\mathrm{KNO}_{3} 0,75 \mathrm{~mol} \mathrm{~L}^{-1}$ e duas gotas de Triton X100. O erlenmeyer que continha o meio de incubação mais os discos foliares foi submetidoa um ambiente com vácuo por trinta segundos, por duas vezes. Rapidamente, em ambiente escuro, o erlenmeyer foi colocado em banho-maria a $30^{\circ} \mathrm{C}$. Retirou-se alíquota de $1 \mathrm{~mL}$ do meio de incubação, aos 10 e aos $30 \mathrm{~min}$, sendo colocado, cada um desses volumes, em uma sol ução com $1 \mathrm{~mL}$ de sulfanilamida $1 \%$ em HCl $3 \mathrm{~mol} \mathrm{~L}^{-1}$ e $1 \mathrm{~mL}$ de água destilada.

Efetuadas as etapas anteriores para todas as amostras, acrescentou-se $1 \mathrm{~mL}$ de n-naftil 0,02\%, agitando-se em vortex. Para estabilização da reação do n-naftil com o nitrito formado, a partir da redução do nitrato, aguardou-se uma hora para a leitura em espectrofotômetro, em comprimento de onda de $540 \mathrm{~nm}$. Os resultados foram correlacionados com uma curva padrão de nitrito, determinando-se a ARN .

A atividade da nitrogenase foi avaliada indiretamente pela atividade de redução do acetileno, segundo método descrito por Hardy et al. (1968). Para isso, coletaram-se as raízes de duas plantas por parcela, que foram limpas do excesso de solo e colocadas, juntamente com os nódulos que delas se desprenderam, em frascos de vidro de $500 \mathrm{~mL}$ hermeticamente fechados. Em seguida, aplicaram-se $50 \mathrm{~mL}$ de acetileno, usando seringa de injeção, com o cuidado de se retirar, previamente, esse mesmovol ume de ar, para nãoalterar a pressão, deixando os frascos incubados por uma hora. Após esse tempo, foram retirados, com o uso de seringa, $10 \mathrm{~mL}$ da atmosfera dos frascos e armazenados em tubos "vacunteiner" de $10 \mathrm{~mL}$. Amostras de $1 \mathrm{~mL}$ dessa atmosfera foram injetadas no cromatrógrafo.

As determinações da redução do acetileno a etileno e o cál culo da atividade da nitrogenase foram feitos de acordo com a técnica descrita por Hardy et al. (1968). Foi utilizado o cromatógrafo a gás model o CG-37D, com detetor de chama denitrogênio a $100^{\circ} \mathrm{C}$ ecol una de vidro com Poropak N, 100 a 120 meshes, 
a $50^{\circ} \mathrm{C}$, com $\mathrm{N}_{2}$ como gás de arraste a um fluxo de

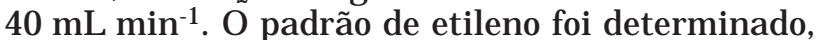
injetando-se no cromatógrafo $1,0 \mathrm{~mL}$ de etileno puro, na concentração de $490 \mathrm{vpm}$. Foram feitas quatro injeções de etileno e obtidos os valores médios de altura dos picos. A atividade da nitrogenase foi calculada pela equação:

- $A N=(V \times U C G \times A t \times F) /\left(i \times h \times n^{\circ}\right.$ plantas $)=$ UCG $\times 0,0430443$, em que AN = atividade da nitrogenase em mmol de $\mathrm{C}_{2} \mathrm{H}_{4} \mathrm{~h}^{-1}$ planta-1; $\mathrm{V}=$ volume do frasco $=500 \mathrm{~mL}$; UCG =área produzida; At $=$ atenuação $=16 ; \mathrm{F}=$ fator de calibração $=$ $1,0761 \times 10^{-5} \mathrm{mmol}$ de $\mathrm{C}_{2} \mathrm{H}_{4}$ por UCG produzida; $\mathrm{i}=$ volume do gás injetado no cromatógrafo $=1 \mathrm{~mL}$; $\mathrm{h}=$ tempo de incubação $=1$ hora e $\mathrm{n}^{\circ}$ plantas $=2$.

As raízes das duas plantas, juntamente com os nódulos desprendidos, após serem usadas na determinação da AN, foram lavadas em água corrente e acondicionadas em sacos plásticos. Os nódulos foram destacados e levados à estufa para secagem a $65-70^{\circ} \mathrm{C}$, determinando-sesua matéria seca.

Na col heita, determinaram-seo número devagens por planta eo número de grãos por vagem, bem como a produtividadede grãos e o peso médio de 100 grãos.

Os dados obti dos foram submetidos a análi ises de variância e de regressão.

\section{RESULTADOSE DISCUSSÃO}

\section{Atividade da nitrogenase}

A atividade da nitrogenase variou muito, visto que os coeficientes de variação foram sempre superiores a $33 \%$, chegando a $57 \%$. No entanto, foi encontrado efeito significativo dos tratamentos com Mo, indicando ter sido o método utilizado satisfatório (Figura 1). Koch et al . (1967), Hungria et al. (1985), Hungria \& Ruschel (1987) também relataram alta variação para os resultados obti dos por essa técnica.

Verificou-se que a atividade da nitrogenase aos 20 DAE (antes da aplicação do molibdênio) foi extremamente baixa, atingindo o valor médio de 3 mmoles $\mathrm{C}_{2} \mathrm{H}_{4} \mathrm{~h}^{-1}$ planta-1 (Figura 1 ). Com a aplicação foliar de Mo aos 25 DAE, a atividade da nitrogenase aumentou, atingindo, aos $40 \mathrm{DAE}$, o

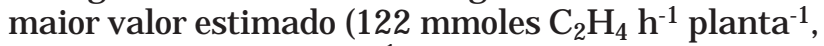
na dose de $120 \mathrm{~g} \mathrm{ha}^{-1}$ de Mo). Esse aumento representou 3,57 vezes em relação à testemunha. Aos $55 \mathrm{DAE}$, o valor máximo calculado foi de 197 mmoles $\mathrm{C}_{2} \mathrm{H}_{4} \mathrm{~h}^{-1}$ planta-1 para a dose de $108 \mathrm{~g} \mathrm{ha}^{-1}$ de Mo, com um acréscimo de 10,40 vezes em relação à testemunha.

A maior diferença na AN entre os tratamentos que receberam adubação foliar com Mo e o tratamento que não recebeu ocorreu nas fases de pleno florescimento do feijoeiro e início do enchimento degrãos, em torno de 55 DAE (Figura 1). Após o florescimento, a AN caiu drasticamente, característica da simbiose feijoeiro - Rhizobium, visto que, após essa fase, a planta diminui substancialmente a translocação de carboidratos para o sistema radicular (Pereira et al., 1984). A queda da atividade da nitrogenase foi mais acentuada no tratamento que não recebeu Mo, ficando evidente o efeito de sua aplicação sobre o aumento e sobre a manutenção da atividade da nitrogenase durante um maior período do ciclo do feijoeiro, o que é de fundamental importância para manter sua fixação biol ógica de $\mathrm{N}_{2}$. Conforme Vieira (1994), a aplicação de Mo aos 25 dias não elimina o

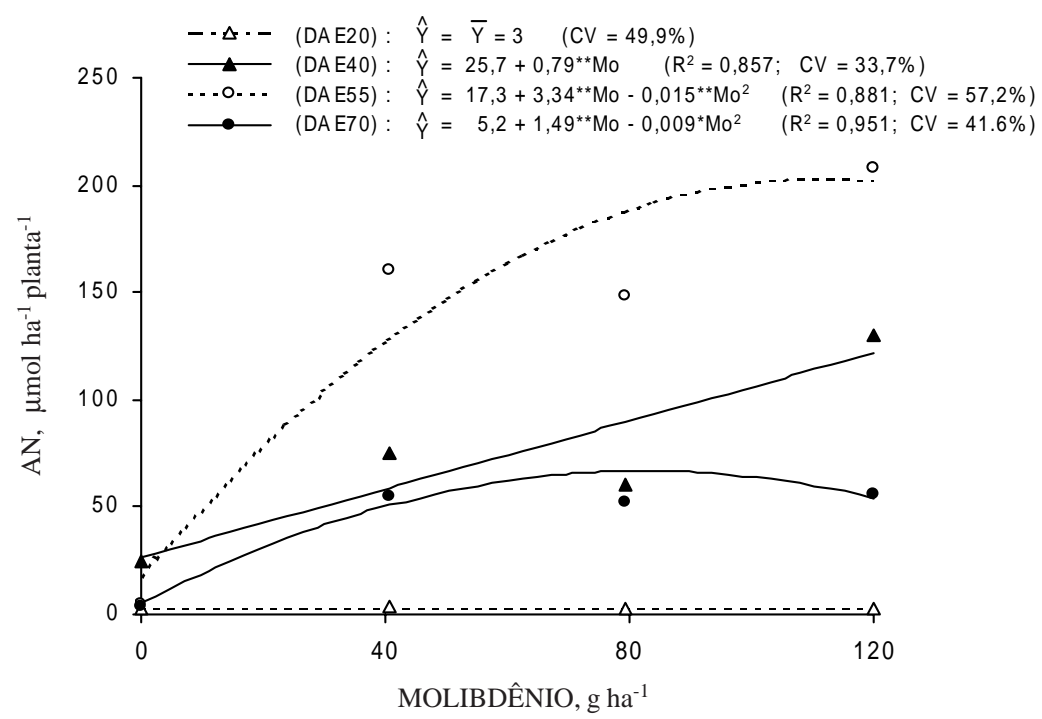

Figura 1. Atividade da enzima nitrogenase (AN) aos 20, 40, 55 e 70 dias da emergência (DAE ) do feijoei ro cv. Ouro Negro, considerando a aplicação foliar de molibdênio. *, ** significativos, respectivamente, a 5 e a $1 \%$ pelo teste $t$. 
problema da depleção de nitrogênio no início do ciclo do feijoeiro, mas faz com que a atividade da nitrogenaseaumentee se mantenha após a aplicação desse nutriente, em al guns casos, por até os 60 dias após a emergência.

\section{Atividade da redutase do nitrato}

Observou-seque, na primeira avaliação, feita aos $20 \mathrm{DAE}$, portanto, antes da aplicação de Mo, a atividade da redutase do nitrato foi muito baixa, com média de 0,650 mmol $\mathrm{NO}_{2}{ }^{-} \mathrm{h}^{-1} \mathrm{~g}^{-1}$ de matéria fresca defol has (Figura 2). Entretanto, com a aplicação de Mo aos 25 DAE, ocorreu aumento significativo da atividade dessa enzima, chegando, na segunda avaliação (40 DAE ), a val ores superiores a seis vezes o encontrado nas plantas que não receberam esse nutriente. $\mathrm{Na}$ tercei ra avaliação, que coincidiu com o flor escimento (55 DAE), os val or es chegaram a ser 16 vezes superiores e, na quarta avaliação, que coincidiu com o enchimento de grãos (70 DAE), os valores chegaram a ser 10 vezes superiores àqueles obtidos nas plantas que não receberam Mo.

O período de mais alta atividade da redutase do nitrato ocorreu entre os 40 e 55 DAE, com queda drástica após esse estádio. Resultados semel hantes foram observados por Hungria et al. (1985).

A redutase do nitrato nas plantas que não receberam adubação foliar com Mo apresentou atividade mai or na primeira coleta (20 DAE) e, com o tempo, decresceu (Figura 2). I sso se explica pela translocação de carboidratos para os grãos em crescimento em detrimento de outros órgãos da planta, como fol has e raízes. Nessa situação, a absorção deN dosolotambém fica menor, predominando sua transl ocação na planta (Hungria et al., 1985).
A atividade da redutase do nitrato (ARN), nas três épocas estudadas após a aplicação do Mo, atingiu o máximo com doses de Mo em torno de $90 \mathrm{~g} \mathrm{ha}^{-1}$ (Figura 2).

Apesar de ser a uréia fonte de nitrogênio usada no plantio, considerando as condições químicas e físicas do solo, tais como: $\mathrm{pH}$ moderadamente ácido e boa aeração, acredita-se que a maior parte do amônio oriundo da degradação da uréia tenha-se convertido a nitrato (Neptune \& Muraoka, 1978), tornando-se necessária boa disponibilidade de Mo para a síntese e ARN para o feijoeiro utilizar eficientemente o N mineral aplicado (Evans, 1956; Felix et al., 1981).

$\mathrm{Na}$ literatura, várias citações afirmam ser a redutase do nitrato uma enzima induzida pelo substrato (Marschner, 1995) eser onitrato o primeiro sinal neste processo. Quando o nitrato está ausente, a síntese e a atividade da enzima permanecem em níveis muito baixos. Entretanto, quando a planta é submetida ao nitrato, a síntese do nitrato redutase rapidamente é induzida, desde que o Mo não seja fator limitante. I sto, provavel mente, aconteceu nos tratamentos que receberam o Mo, dado o grande incremento observado na atividade dessa enzima.

\section{Matéria seca de nódulos}

Observou-se incremento na matéria seca de nódulos (MSN) com o desenvolvimento do feijoeiro. Aos 20 DAE , a MSN foi de 19 mg planta-1, atingindo $100 \mathrm{mg} \mathrm{planta}^{-1}$ aos $40 \mathrm{DAE}$, independentemente da aplicação de Mo (Figura 3). Entretanto, a aplicação feita aos 25 DAE condicionou a manutenção do crescimento dos nódulos, apresentando um efeito quadrático com máximo aos 55 DAE (fase do

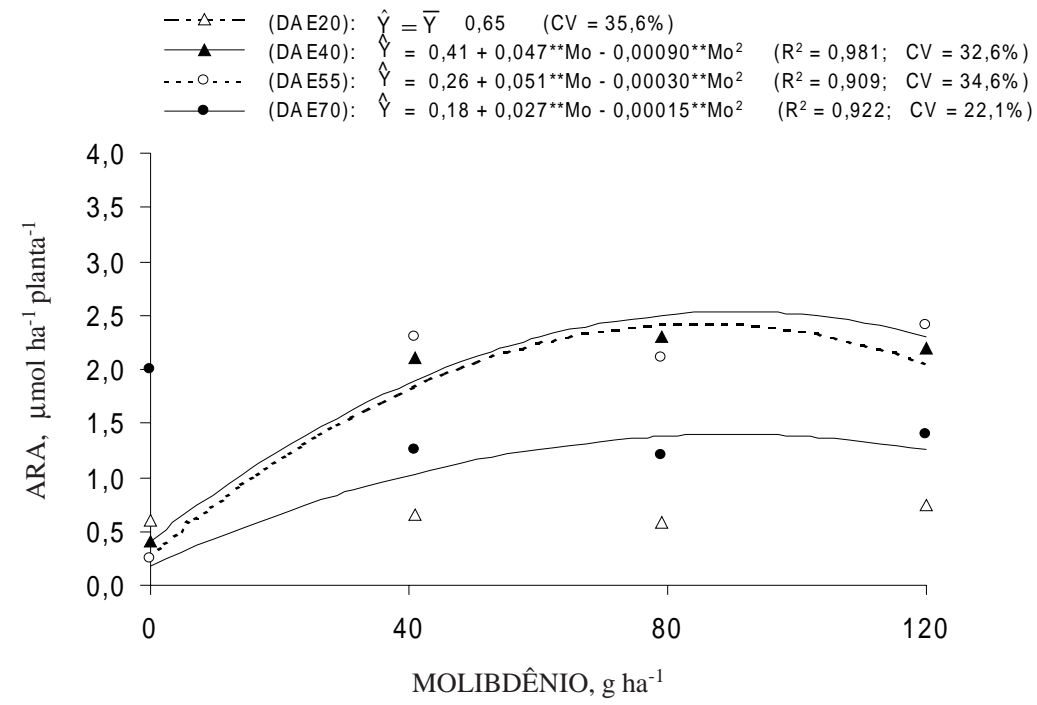

Figura 2. Atividade da enzima redutase do nitrato (ARN) aos 20, 40, 55 e 70 dias da emergência (DAE) do feijoeiro cv. Ouro Negro, considerando a adubação foliar com molibdênio. ** significativo a $1 \%$ pelo teste t. 


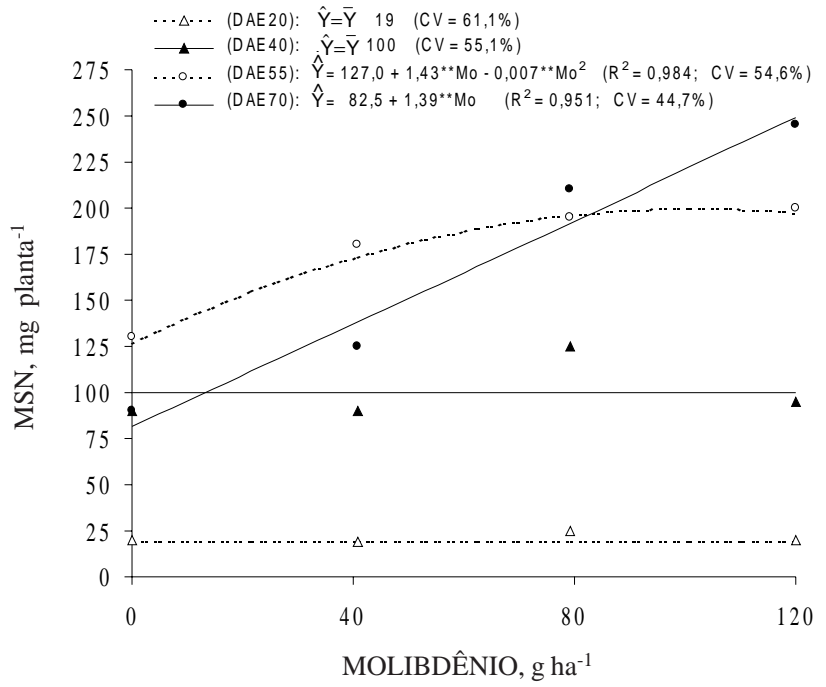

Figura 3. Matéria seca de nódulos (MSN) aos 20,40, 55 e 70 dias da emergência (DAE) do feijoeiro cv. Ouro Negro, considerando a adubação foliar com molibdênio. ** significativo a $1 \%$ pelo teste $t$.

florescimento), com o valor máximo estimado de $201 \mathrm{mg}$ planta-1, proporcionado pela dose $102 \mathrm{~g} \mathrm{ha}^{-1}$ de Mo.

Notratamento quenão recebeu Mo, os nódulos, no período deenchimento degrãos, mostravam-seescuros e, em alguns casos, em decomposição, indicando senescência precoce, com provável diminuição e até paralisação da fixação biológica de $\mathrm{N}_{2}$ (Hungria et al., 1997). J á nos tratamentos que receberam Mo, os nódulos apresentavam-se, nessa fase, com maior tamanho e com coloração interna avermel hada, indicando serem ainda funcionais, fato comprovado pela maior atividade da nitrogenase, em relação ao tratamento que não recebeu Mo (Figura 1).

Os menores resultados da AN, ARA ematéria seca de nódulos no tratamento que não recebeu Mo parecem estar associados a um menor ciclo vegetativo do feijoeiro, visto que as plantas começaram a florescer primeiro, apresentaram crescimento reduzido após o florescimento e atingiram o período de colheita rapidamente. Aos $40 \mathrm{DAE}$, as plantas apresentavam clorose intensa, que progrediu a partir das folhas inferiores, atingindo toda a planta com o aumento da idade.

\section{Produtividade e componentes da produção}

A aplicação foliar de Mo proporcionou resposta quadrática à produtividade de grãos, ao número de vagens por planta, ao número de grãos por vagem e ao peso de 100 grãos (Figura 4).

A máxima eficiência técnica foi conseguida com a dose de $80 \mathrm{~g} \mathrm{ha}^{-1}$ de Mo e com produtividade estimada de $1.893 \mathrm{~kg} \mathrm{ha}^{-1}$. O tratamento que não recebeu Mo apresentou média de $448 \mathrm{~kg} \mathrm{ha}^{-1}$. Portanto, a aplicação de Mo aumentou em 3,23 vezes a produtividade. Esse resultado está de acordo com os encontrados por Amane(1994), Berger et al. (1995) eAmane (1997).

Para a dose de $80 \mathrm{~g} \mathrm{ha}^{-1}$ de Mo, correspondente à máxima eficiência técnica para produtividade, os

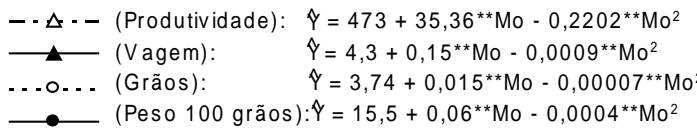

$\mathrm{R}^{2}=0,988$

$R^{2}=0,990$

$\mathrm{R}^{2}=0,999$

$\mathrm{R}^{2}=0,960$

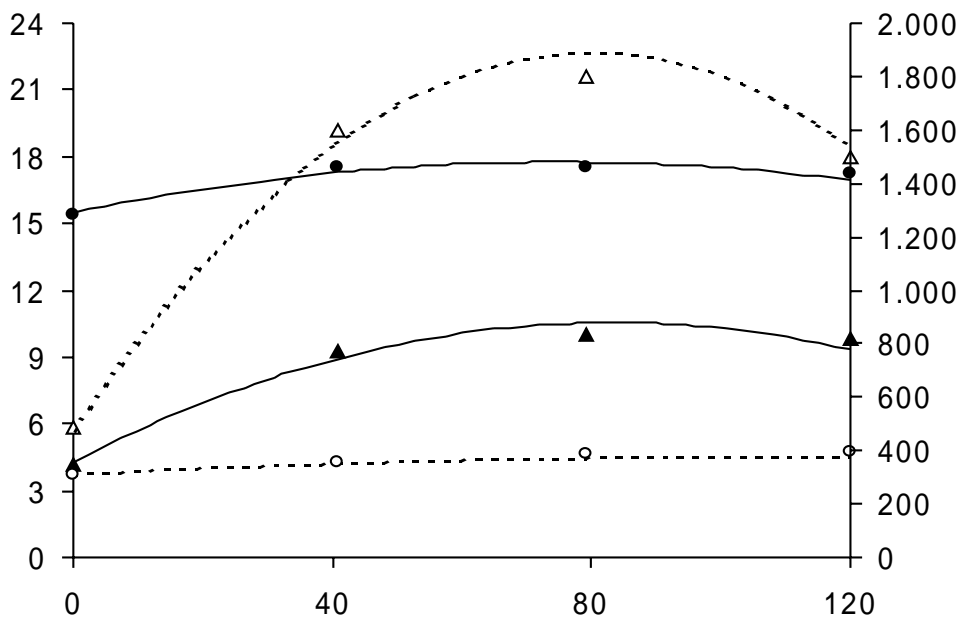

Figura 4. Produtividade de grãos, número de vagens por planta, número de grãos por vagem e peso de 100 grãos do feijoeiro cv. Ouro Negro, considerando a adubação foliar com molibdênio. ** significativo a $1 \%$ pelo teste $t$. 
val ores estimados para os componentes da produção foram de 10,7 vagens por planta, 4,7 grãos por vagem e o peso de 100 grãos de 17,74 g. Assim, a aplicação foliar de Mo aumentou em 1,54 vez o número de vagens, em 0,23 o número de grãos por vagem e em 0,15 o peso de 100 grãos.

As respostas encontradas no peso médio dos grãos corroboram as relatadas por Amane (1997) em feijoeiro cv. Ouro Negro, cultivado em Visconde do Rio Branco (MG), ondea aplicação de Mo aumentou o peso médio dos grãos em 0,13, enquanto a aplicação de nitrogênio aumentou somente em 0,05. Araújo et al. (1987) e Berger (1995) também encontraram resultados semel hantes.

Nem sempre foram encontradas respostas positivas na produtividade do feijoeiro com a aplicação de Mo em outras regiões do País (Corrêa, 1989; Castro et al., 1994; Vieira et al., 1998). Acreditase que tal fato se deva a maior disponibilidade deste nutriente no solo (Castro et al., 1994) ou aos teores relativamente al tos de Mo das sementes do feijoeiro, suficientes para prevenir a deficiência na lavoura plantada (Vieira,1986; Vieira, 1989; Brodrick et al., 1992).

É possível que o acréscimo de produtividade verificado neste trabal ho esteja relacionado não só com o efeito conjunto do aumento da atividade da nitrogenase e, conseqüentemente, com o incremento na fixação biológica de $\mathrm{N}_{2}$, mas também com o aumento da ARN e, conseqüentemente, coma melhor utilização do nitrato absorvido pelas plantas adubadas com $\mathrm{Mo}$.

\section{CONCLUSÕES}

1. A aplicação foliar deMo aumentou as atividades da nitrogenase e da redutase do nitrato em feijoei ro.

2. A aplicaçãofoliar deMoproporcionou aumentos da produtividade de grãos em até 3,23 vezes a produtividade da testemunha.

3. A matéria seca de nódulos, onúmero de vagens por planta, o número de grãos por vagem e o peso de 100 grãos foram positivamente influenciados pela aplicação de Mo.

\section{LITERATURA CITADA}

AMANE, M.I.V. Adubação nitrogenada e molíbdica da cultura do feijão (Phaseol us vulgaris L.) na Zona da Mata de Minas Gerais: efeitos de doses, calagem e rizóbio. Viçosa, Universidade Federal de Viçosa, 1997. 83p. (Tese de Doutorado)

AMANE,M.I.V. Respostas de cultivares de feijão (Phaseolus vulgaris L.) às adubações nitrogenada e molíbdica. Viçosa, Universidade Federal de Viçosa, 1994. 70p. (Tese de Mestrado)
ARAÚJ O, G.A.A..; FONTES, L.A.N.; AMARAL, F.A.L. \& CONDÉ, A.R. Influência do molibdênio e do nitrogênio sobre duas variedades de feijão (Phaseolus vulgaris L.). R. Ceres, 34:333-339, 1987.

BERGER, P.G. Adubação molíbdica na cultura do feijão (Phaseol us vul garis L.): doses, épocas e modos de aplicação. Viçosa, Universidade Federal de Viçosa, 1995. 75p. (Tese de Doutorado)

BERGER, P.G.; VIEIRA, C.; ARAÚJ O, G.A.A. \& CASSINI, S.T.A. Pel etização de sementes de feijão (Phaseolus vulgaris L.) com carbonato de cálcio, rizóbio e molibdênio. R. Ceres, 42:562-574, 1995.

BRODRICK, E.J .; SAKALA, M.K.\& GILLER, K.E. Molybdenum reserves of seed, and growth and $\mathrm{N}_{2}$ fixation by Phaseolus vulgaris L. Biol. Fertil. Soil, 13:39,1992.

CASTRO, A.M.C.; BOARETO, A.E. \& NAKAGAVA,J . Tratamento de sementes de feijoeiro (Phaseolus vulgaris L.) com molibdênio, cobalto, metionina e vitamina B1. R. Bras. Sementes, 16:26-30,1994.

COELHO, F.C. Efeitos do nitrogênio e do molibdênio sobre as culturas do milho e do feijão em monocultivo eem consórcio. Viçosa, Universidade F ederal de Viçosa, 1997. 136p. (Tese de Doutorado)

CORREA, J .R.V. Efeitos de inoculação, Mo e Co sobre o feijoei ro comum (Phaseolus vulgaris L.) cv. Carioca. Lavras, Escola Superior de Agricultura de Lavras, 1989. 86p. (Tese de Mestrado)

DALLPAI, D.L. Determinação espectrofotométrica de molibdênio em sol o e tecido vegetal e adsorção de mol ibdato em al guns solos de Minas Gerais. Viçosa, Universidade Federal de Viçosa, 1996. 56p. (Tese de Mestrado)

EMPRESA BRASILEIRA DE PESQUISA AGROPECUÁRIA EMBRAPA. Serviço Nacional de Levantamento e Conservação de Solos. Manual de métodos de análise de solos. Rio de J aneiro, 1979. não paginado.

EVANS, H.J. Role of molybdenum in plant nutrition. Soil Sci., 81:199-208, 1956.

FELIX, J.F.; OBATON, M. \& MESSIAEN, C.M. Nitrateredutase and nitrogenase activities of common beans (Phaseolus vulgaris L.) from different geografic locations. Plant Soil, 63:427-438, 1981.

HAGEMAN, R.H. \& REED, A.J . Nitrate reductase from higher plants. Methods Enzimol., 69:270-280, 1980.

HARDY, R.W.F.; HOLSTEN, R.D.; J ACKSON, E.K. \& BURNS, R.C. Theacetylene ethyleneassay for $\mathrm{N}_{2}$ fixation: laboratory and field evaluation. Plant Physiol., 43:1185-1207, 1968.

HUNGRIA, M.; NEVES, M.C.P. \& VICTORIA, R.L. Assimilação do nitrogênio pel o feijoeiro. I. Atividade da nitrogenase, da redutase do nitrato e transporte do nitrogênio na seiva do xilema. R. Bras. Ci. Solo, 9:193-200, 1985.

HUNGRIA, M. \& RUSCHEL, A.P. Atividade da nitrogenase e evolução do hidrogênio pel os nódul os de Phaseol us vul garis. R. Bras. Ci. Solo, 11:269-274, 1987.

HUNGRIA, M.; VARGAS, M.A.T. \& ARAÚJ O, R.S. Fixação biológica do nitrogênio em feijoeiro. In: VARGAS, M.A.T. \& HUNGRIA, M., eds. Biologia dos solos dos cerrados. Planaltina, Empresa Brasileira de Pesquisa Agropecuária, 1997. p.187-294. 
J UNQUEIRA NETTO, A.; SANTOS, O.S.; AIDAR, H. \& VIEIRA, C. Ensaios preliminares sobre a aplicação de molibdênio e cobalto na cultura do feijão (Phaseol us vul garis L.). R. Ceres, 24:628-633, 1977.

KOCH, B.; EVANS, H.J . \& RUSSEL, S. Reduction of acetylene and nitrogen gas by bries and cell free extracts of soybean root nodules. Plant Physiol., 42:466-467,1967.

MARSCHNER, H. Mineral nutrition of higher plants. London, Academic Press, 1995. 889p.

NEPTUNE, A.L.M. \& MURAOKA, T. Aplicação de uréia $-{ }^{15} \mathrm{~N}$ em feijoeiro (Phaseolus vulgaris L.) cultivar Carioca. R. Bras. Ci. Solo, 2:51-55,1978.

PEREIRA, P.A.A.; ARAÚJ O, R.S.; ROCHA, R.E.M.\& STEINMETZ, S. Capacidade de genótipos de feijoeiro de fixar $\mathrm{N}_{2}$ atmosférico. Pesq. Agropec. Bras., 19:811-815, 1984.

VETTORI, L. Métodos de análise de solo. Rio de J aneiro, EPEMA, 1969. 24p. (Boletim Técnico, 7)
VIEIRA, C. Cultura do feijão. Viçosa, Universidade Federal de Viçosa, 1978. 146p.

VIEIRA, C.; NOGUEIRA, A.O. \& ARAúJ O, A. A adubação nitrogenada e molíbdica na cultura do feijão. R. Agric., 67:117-124, 1992.

VIEIRA, R. F. Desempenho de sementes de feijão provenientes de diferentes níveis de adubação. Pesq. Agropec. Bras., 21:1161-1168, 1986.

VIEIRA, R.F. Aplicação foliar de molibdênio e seu efeito nas atividades da nitrogenase e redutase do nitrato no feijoeiro em campo. Piracicaba, Escola Superior de Agricultura Luiz de Queiroz, 1994.188p. (Tese de Doutorado)

VIEIRA, R.F. Efeito da calagem sobre a composição química, qualidade fisiológica e desempenho, no campo, de sementes de feijão. Pesq. Agropec. Bras., 24:409-415, 1989.

VIEIRA, R.F.; CARDOSO, E.J .B.N.; VIEIRA, C. \& CASSINI, S.T.A. Foliar application of molybdenum in common beans. I. nitrogenases and reductase activities in a soil of high fertility. J . Plant Nutr., J apan, 21:169-180.1998. 